\title{
EDITORIAL
}

\section{Educación en tiempos de crisis sanitaria: pandemia y educación}

\author{
Alex Gutierrez-Moreno ${ }^{1}$ (D) \\ 1. Docente Asociado. Universidad del Magdalena, Santa Marta, Colombia. Correo electrónico: agutierrez@unimagdalena.edu.co
}

\begin{abstract}
a pandemia de COVID-19 ha derivado en una crisis internacional que reformó las agendas y puso en primer orden la salud Ly la atención a los efectos concomitantes en la vida social, la economía y la política. En efecto, este es considerado como el mayor desafío desde la segunda Guerra Mundial (PNUD, 2020). La pandemia fue declarada el pasado 11 de marzo (OMS, 2020) se propagó en días y pocas semanas, a diferencia de la ocurrida en 1918, que se transmitió en meses. Los cambios demográficos y la gran movilidad ha hecho a la humanidad más vulnerable a las pandemias como la producida por el coronavirus (Kaneda y Greenbaum, 2020).
\end{abstract}

Los efectos de esta en particular son inmensos, no solo por la morbilidad y la mortalidad vinculadas que ya la convierten en calamidad pública internacional, sino por los efectos colaterales en la productividad, el empleo y los ingresos de las familias. Esto hace de la economía de las naciones una víctima con consecuencias devastadoras en el frágil estado de cosas, tanto en países desarrollados como también, y más fuertemente, en países en desarrollo. Al disminuir el consumo y funcionar a media máquina la producción de bienes y servicios a nivel mundial, el ingreso se afecta gravemente.

Los empleos, tal como se conocieron en el siglo XX - los cuales ya estaban amenazados por los escenarios que se visionan con el advenimiento de la IV Revolución Industrial (Schwab, 2015) o la Segunda Era de las Máquinas (Brynjolfsson y McAfee, 2014)—, se enfrentan a un paro descomunal que profundizará las desigualdades. Así, acabar con la pobreza que se incrementará inexorablemente (780 millones de personas viven por debajo del umbral de pobreza según la ONU, 2019), supondrá redoblar los esfuerzos actuales.

Los retos para la humanidad ya son monumentales y complejos, y están consignados en los Objetivos de Desarrollo Sostenible (ONU, 2015). Todo ello derivado de factores como el crecimiento poblacional que presiona el consumo de comida, agua y energía en el planeta; el uso intensivo de los combustibles fósiles y la concentración de la riqueza que conlleva al crecimiento de las desigualdades, las cuales están asociadas a decisiones y políticas gubernamentales. La crueldad de la desigualdad, cuyo origen Piketty $(2018 ; 2019)$ ubica en la política y las ideologías que la sustentan, más que en la economía, puede experimentar un incremento sofocante para los países que no gestionen de manera adecuada la crisis. Quizá por eso el PNUD (2020) ha adoptado la consigna: "La humanidad necesita liderazgo y solidaridad para vencer al coronavirus", que se suma a los llamados a la cooperación (Harari, 2020; ONU, 2020) y a la solidaridad, antes que al miedo y la xenofobia, y propagar la amabilidad, el respeto y el trato digno (Guterres, 2020).

Hasta 2019, las posibles pandemias eran un supuesto bien fundamentado: se preveían, pero no hubo suficiente atención. La cuestión no era si sucedería una pandemia, sino cuándo y dónde empezaría. La evidencia muestra que los gobiernos nacionales y los organismos multilaterales no atendieron esas advertencias. Lo que sucedió puede sumarse a las anticipaciones o profecías descartables (Braslavsky, 2006), que son tesis sobre tendencias del desarrollo humano en el campo económico, político y social, que se toman como naturales y, desde ese punto de vista, como inevitables, aunque comportan 
la acción humana y en esa dimensión puede ser cambiada por la conducta que se adopte. Por tanto, pueden ser conjuradas si se toman las mejores decisiones y se saben gobernar (Gutiérrez, 2007).

En ese marco, Braslavsky, basada en los postulados de Schwartz (2003), señala que la calidad de la educación es aquella que permite a todas las personas aprender lo necesario para evitar las profecías descartables, además de aprovechar las sorpresas inevitables. En este sentido, la educación es considerada como factor esencial de transformación social y como una capacidad primordial, ya que la educación es uno de los medios más importantes cuando se trata de proveer herramientas para poder obtener realizaciones (Sen, 2000). Así mismo, como centro de la expansión de la capacidad humana (Sen, 2002), pues contribuye a una vida más libre y realizable (Sen, 1997). Al respecto, Stiglitz y Greenwald (2014), reconociendo la importancia del papel de la educación, postulan la creación de una sociedad de aprendizaje como nuevo modelo de desarrollo endógeno. Por ello, puede sostenerse que la educación tiene un papel preponderante en esta crisis, al igual que en otras emergencias.

Sin embargo, esta pandemia ha representado para los sistemas educativos un abrupto cambio para el que no se estaba avisado. Fue inesperado, por lo que no estar preparado para ello no significa falencia, sino que se trata de una ruptura, puesto que las instituciones educativas actuaban en sus procesos habituales, planeados bajo ese presupuesto de normalidad: ingreso, desarrollo y culminación de procesos de enseñanza.

Aunque se trata de un sistema celoso de entrar en grandes revoluciones y sigue siendo funcionalista (Parsons, 1985), reproductivo social (Bourdieu y Passeron, 1977) o resistente al cambio de parte de profesores y directivos, y aunque sus consignas parecen perennes - no obstante que se trata de un factor social que impulsa y moviliza los cambios-, en las últimas décadas enfrenta disrupciones, tanto por el carácter de las nuevas generaciones como por los avances tecnológicos y el efecto de eventos extensivos como la globalización de la economía y el avance en las telecomunicaciones. Pero la pandemia, con su correlato de medidas de aislamiento social, como fase primera de prevención es, indudablemente, un contexto extraño y azaroso.

De una educación fundamentalmente presencial, el mundo, abierto ya a la enseñanza a través de medios digitales como algo innovador — que resuelve las grandes distancias y las diferencias de agendas de sus actores, entre otras ventajas-, ahora vive como cotidiana la educación digital. Esta solución, sin embargo, está reservada para aquellas poblaciones que han resuelto la brecha digital, tanto porque cuentan con infraestructura apropiada o bien su capacidad económica posibilita su adquisición. Aunque la interacción remota digital no es la única vía, es la más utilizada en este período. En cualquier caso, no son los medios, son las circunstancias: al estrés y la ansiedad que la pandemia produce ante el riesgo cierto de contagio y el posible grave padecimiento, incluso la muerte, se suma el confinamiento obligado que restringe las libertades de las que todos gozaban y hacían "normal" la vida de las personas.

Los efectos en la conducta humana son disímiles y significativos. Estos abarcan la adaptación constructiva, el estrés, la ansiedad y hasta las crisis paranoicas derivadas de la infoxicación atribuible a la amplia difusión de la problemática por medios tradicionales o por redes sociales, que incluye desde fake news hasta la negación personal y/o institucional y, en consecuencia, la adopción de comportamientos de alto riesgo: algunos por no seguir las recomendaciones sanitarias y otros por la ignorancia de las causas de la enfermedad o por las lealtades culturales y sociales (festejos, rituales funerarios, encuentros furtivos...). También hay personas con conductas adaptativas que consiguen desarrollar actividades propias de sus aficiones, trabajo o estudio y avanzan satisfactoriamente; algunos encuentran la oportunidad para llevar sus ideas a otro nivel, consiguen soluciones y acciones creativas y productivas, o bien ponerse al día. Entre los negacionistas, lo más grave se relaciona con aquellas personas que tienen algún nivel de poder, medio o máximo, incluyendo el político en una ciudad, departamento o comunidad, e incluso país; puesto que sus decisiones tienen repercusiones trascendentales que pueden significar el colapso del sistema sanitario y un impacto negativo en la economía, con todo, efectos sociales, políticos y financieros. En esa circunstancia, niños y jóvenes escolarizados se enfrentan ante este enorme desafío.

En este escenario se validan cuestionamientos acerca de qué hacer y cómo afrontar la situación, con el atenuante de que no se trata de un evento de corto plazo, sino de mediano plazo, dado que se hipotetizan rebrotes del contagio. Al mismo tiempo 
y con igual importancia se reivindican los fines y los propósitos de la educación: qué educamos, para qué y qué estándar podemos alcanzar. Importa aquí el aprendizaje, aunque no se trata de la discusión de si en el centro debe estar el docente con su enseñanza, quien antes se posicionaba como eje del proceso, o el aprendiz, o más bien el resultado del aprendizaje. Estos enfoques dejan a la familia fuera de lugar. Por eso, esa discusión carece de sentido cuando debiera considerarse el sistema que educa como un holón, compuesto por otros holones, y no como una estructura de centros gravitacionales. Esto último permite que se asuma como en efecto es: un fenómeno holístico determinado por un conjunto de factores interdependientes de cuya calidad depende su eficacia. Solo de ese modo se podrían brindar oportunidades de desarrollo de capacidades y darse garantías de derecho a la educación.

Tan importantes son las decisiones claves y oportunas de los administrativos y/o autoridades educativas, que con decretos y resoluciones definen un estado de cosas, como la implicación de los padres o los cuidadores, quienes deben sortear situaciones laborales y económicas, así como ambientales en su entorno familiar y, naturalmente, la disciplina y autogestión del aprendizaje de los estudiantes. Esta autonomía estudiantil puede ser un valioso descubrimiento para el sistema, aunque se haya apelado a ello desde hace mucho, incluso, cuestionando el rol del docente. Esto provocó el paso de un modelo expositivo, fundado en los contenidos, a un modelo de cooperación y acompañamiento del aprendizaje.

En estos momentos de pandemia es probable que se presenten crisis tanto en estudiantes como en los profesores, como se ha denunciado en varios países, donde se quejan unos y otros, incluso los padres, por la alta carga de trabajo que devino con el cambio frente a la emergencia sanitaria. Las preocupaciones, por tanto, abundan. Si se trata de familias y/o estudiantes vulnerables, aquellos cuyos ingresos no son suficientes para satisfacer sus necesidades, o han sido desplazados por la violencia, víctimas de catástrofes, o han perdido el empleo, viven en zonas rurales de difícil acceso, con baja infraestructura eléctrica e inexistencia de conexión a internet, o se trata de estudiantes con algún tipo de discapacidad, entre otras desventajas, la situación se complejiza aún más y supone un mayor reto. Las decisiones y las actuaciones deben corresponder a estas realidades, de tal manera que no se vulnere el derecho a la educación, convirtiendo el sistema educativo más inequitativo de lo que es, por ejemplo, en los países en desarrollo. Se trata entonces de una situación inédita que requiere de propuestas creativas y viables.

\section{Referencias bibliográficas}

Bourdieu, P. y Passeron, J. (1977). La reproducción. Elementos para una teoría del sistema de enseñanza. Barcelona: Laia.

Braslavsky, B. (2006). Diez factores para una Educación de Calidad para Todos en el Siglo XXI. Riece 4(2), 84-101.

Brynjolfsson, E. y McAfee, A. (2014). The Second Machine Age. Work, progress, and Prospecty in a Time of Brilliant Technologies. New York-London: Norton \& Company.

Guterres, A. (2020). Solidaridad contra el odio propagado por el coronavirus. Recuperado de https://www.un.org/es/coronavirus

Gutierrez, A. (2007). El valor de la calidad de la educación. En R. Posada (Presidente), II Congreso Nacional por una Educación de Calidad, Colombia-Santa Marta.

Harari, Y. (15 de marzo de 2020). In the Battle Against Coronavirus, Humanity Lacks Leadership. Time. Recuperado de https://time.com/5803225/yuval-noah-harari-coronavirus-humanity-leadership/

Kaneda, T. y Greenbaum, Ch. (2020). How Demographic Changes Make Us More Vulnerable to Pandemics Like the Coronavirus. Recuperado de https://www.prb.org

OMS (2020). Alocución de apertura del Director General de la OMS en la rueda de prensa sobre la COVID-19 celebrada el 11 de marzo de 2020. https://www.who.int/es/dg/speeches/detail/who-director-general-s-opening-remarks-at-the-mediabriefing-on-covid-19---11-march-2020

ONU (2015). Agenda 2030 sobre desarrollo sostenible. Recuperado de https:un.org/susteinabledevelopment

ONU (2019). Acabar la pobreza. Recuperado de https://www.un.org/es/sections/issues-depth/poverty/index.html

ONU (2020). La enfermedad del coronavirus, una emergencia de salud mundial. Recuperado de https://www.un.org/es/coronavirus

Parsons, T. (1985). La clase como sistema social: Algunas de sus funciones en la sociedad americana. En A. Grass (Ed.), Sociología de la educación. Textos fundamentales (pp. 53-78). Madrid: Narcea. 
Piketty, T. (2018). La economía de las desigualdades. España: Anagrama.

Piketty, T. (2019). Capital e ideología. Barcelona: Deusto.

PNUD (2020). COVID-19: la pandemia. Recuperado de https://www.undp.org/content/undp/es/home/coronavirus.html

Schwab, K. (2015). The Fourth Industrial Revolution. What It Mean and How to Respond. Recuperado de https://www.foreignaffairs.com

Schwartz, P. (2003). Inevitable surprises: Thinking ahead in a time of turbulence. New York: Gotham Books.

Sen, A. (1997). Human capital and human capability. World Development, 25(12), 1959-1961. Recuperado de http://www.sciencedirect.com

Sen, A. (2000). El desarrollo como libertad. Gaceta Ecológica, (55), 14-20.

Sen, A. (2002) Basic education and human security. Recuperado de www.humansecuritychs.org/activities/outreach/Kolkata.pdf

Stiglitz, J. y Greenwald, B. (2014). Creating a Learning Society: A New Approach to Growth, Development, and Social Progress. New York: Columbia University Press. 